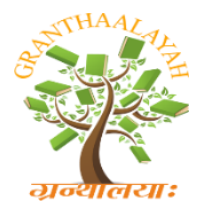
INTERNATIONAL JOURNAL OF RESEARCH -
GRANTHAALAYAH
A knowledge Repository

Science

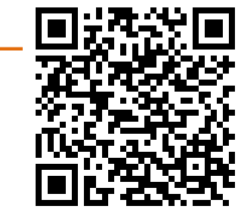

\title{
IMPACT OF STREETSCAPING ON HUMAN PSYCHOLOGY
}

\author{
Kavya Trivedi ${ }^{* 1}$, Ar. Soma Anil Mishra ${ }^{* 2}$, Kunika Gehlot ${ }^{* 3}$ \\ $* 1, * 2,{ }^{* 3}$ Department of Architecture, SDPS College of Architecture, India
}

\begin{abstract}
This research is subjected to the study of the impact of street scape on human psychology. The study mainly focuses on the importance of the design of sidewalks on the street so that it can't become the space for the criminal activities as described by the journalist jane Jacobs. The research also aims to study the role of urbanization in changing the street scaping of the cities. The study comprises of the statistical data which is the output of the survey conducted by the researcher and live case study of the streets of two cities i.e. Chandigarh and Pune.42\% Part of the city are imbued with streets and therefore they play a vital role on the psychology of a human being. Keeping this in mind, the research is made on how streets could be designed in a manner that create the surrounding safe and happier to live.
\end{abstract}

Keywords: Architecture; Urbanization; Human-Psychology; Environmental Psychology; Street Scaping.

Cite This Article: Kavya Trivedi, Ar. Soma Anil Mishra, and Kunika Gehlot. (2018). "IMPACT OF STREETSCAPING ON HUMAN PSYCHOLOGY." International Journal of Research - Granthaalayah, 6(10), 158-168. https://doi.org/10.29121/granthaalayah.v6.i10.2018.1173.

\section{Introduction}

Urbanization conditions the changes observed in human behavior, as a number of occupants from rural areas are migrating in cities for various reasons, cities are rapidly experiencing growth in its multitude, hence turning out to be crowded which is further resulting in lack of resources. What authorizing the assembly of humans the most is trending upgradation of livelihood and social status which keeps each individual occupied in offices and work henceforth escalating the issues like less interaction between people, crime, disintegration of families, stressful life, poor social network, etc. Correspondingly, urbanization brings out social and cultural changes in community life which also symbolizes modernization.

Every place encountering our presence, plays a vital role in leveraging our existence. According to environmental psychology, there is an unavoidable relationship between human behavior and its habitual livelihood. From various researches it is quite clear that environment influences human behavior in several prospects. Integrating with identical disciplines like architecture and town planning, many researchers scrutinized the role of certain characteristics of the environment 
demonstrating a broad meaning. For example, landscapes and infrastructure of neighborhood and cities of habitation in relation with psycho-social constructs like stress, sense of safety etc. The mindset of habitants of a locality is shaped by the nature and type of environment in which they live. (1)(2)

Streets and alleys as a major connecting space of any society or build environment as well as accessed by humans of every class and creed, effects and change human psychology. Therefore, it is necessary to examine the function and role of the street within the urban fabric so that it could become the important element in enhancing the prospects of betterment in human's life. (Jacobs, 1961) (3). The street creates a link between buildings either way; within the street or in the city at large scale. As a link it facilitates the movement of people as pedestrians or vehicles within the street. People spend most of their time on streets while travelling from one place to another so, it puts an impact on human brain. If the streets have no traffic everyone will enjoy to ride on that street and if the street have more greenery and different elements like sitting space, swings, etc. which could be appreciated then everyone would like to walk and spend time on that street. Heavy traffic, negotiation of crowded sidewalks, unwanted crowd, and various thug cases arising on the street are making them unsafe for the public. All these issues lead to mental stress and various psychological disorders hence designing of streets needs improvisation.

\section{Streets}

Streets are the lifeline of the city; $42 \%$ part of city are streets. The streets are becoming safer and secure from the perspective of mobility, it means streets are being retrofitted but there is a need to reimagine the street designing according to urban ecology. Let's look at an example of an Indian rural streets: every kind of activities takes place on the street like walking, driving, hanging out. It is a place to see and be seen, it is a place to socialize, to eat and drink, it is a place to make things and mend them, it's a place to preach and pray it's a place for playing, it's a place for everything. It is where the works of the neighborhood are visible, it's where the neighborhood ecology is visible. (4)

A Street is a place to gather, meet, share, and relax, a place to learn about social skills and cooperation, about the city, about the nature. It is a place to engage and exchange ideas and to understand the responsibilities and duties. The number of groups that use the streets are very diverse, rich and poor, the mother with infants and the homeless, there are vendor selling newspapers and panhandlers. (4)

The street's expressive function also includes its use as a site for the casual interaction, including recreation, conversation, and entertainment, as well as its used as a site for ritual observances. The street, however, is also a common area which serves a group, not just one family; the types of neighbors are essential in this quest for self-esteem. Many changes have taken place recently in the social patterns of life in cities due to westernization. For example, many housewives would walk to the shop, they would also walk the children to school. Now the housewives' role has changed and she may be the breadwinner and head of a single parent family or a coworking family partner. More trips are now made by car to the supermarket, the school, and leisure outings. whether male or female young or old a higher number of social interactions occur at the destination rather than during the trip. In the design of cities, it would be unwise to ignore these changes which 
have occurred. Empty streets, as Jacob points out, can lead to the public domain being donated to the thug, mugger and rapist (Jacobs, 1961) (3). Family security is served well by the home on a plot enclosed on three sides by neighboring plots with just one access point from the road for pedestrian and the family car. The street scene is completed with small front Gardens, Low hedges, and protruding Bay Windows. The overlooked street becomes the 'owned' semi-public domain of a local community. (Moughtin) (5)

The form of the street can be analyzed in terms of a number of Polar qualities such as straight or curved, long or short, wide or narrow, enclosed or open, formal or informal. Street form can also be analyzed in terms of scale, proportion, contrast rhythm or connection to other Streets and Square. One should feel ease in a space where gaze does not lose in infinity. The absolute dimensions of the street must therefore be kept within reasonable proportions, when the street is long and wide with houses on a common frontage, it is most difficult to obtain a sense of enclosure. If a Street or a section of a street is to possess the quality of enclosure then it must be considered to have three main elements, an entrance, the place itself and the termination or exit. Since the street is also a path and a path is two directional, the place must terminate or close in two directions. The street should have the feeling of enclosure. The streets which are straight never ending gives the feeling of lost in it, such kind of streets are usually not safe. (Moughtin)(5)

The following are the type of street that can be treated according to its use (6):

Alleys: Alleys are small- scale streets that typically only carry low numbers of vehicles accessing adjacent properties. Their character varies across the city, from residential to service alleys. Hence, it should be designed to a pedestrian- scale, speed and level of detail wherever possible, to calm traffic and emphasize pedestrian use. Alleys may also include seating, landscaping and pedestrian lighting to create usable public space.

Residential Throughways: Residential throughways are those which have fast moving traffic with residential land uses. They are often not designed to serve residential uses, and can be unpleasant to walk or live along, streetscape improvements should focus on buffering the sidewalk and adjacent homes from vehicles passing in the street and providing a generous, useable public realm through landscaping, curb extensions or widened sidewalks.

Neighborhood Residential: Neighborhood residential streets are quieter residential street with low traffic volumes and speeds. Though they have low levels of activity relative to other street types, they play a key role to support to social life of a neighborhood. Residential streets should be safe and comfortable. Improvement should focus on slowing traffic, providing useable space and amenities, and making improvements that encourage residents to take pride and ownership of the streetscape outside their front door.

Neighborhood Commercial: These are the streets that are used as the place to hang out, shop and play on the weekends. Short term parking for customers and space for loading facilities are essential components of commercial districts. However, parking and loading facilities often compete for the same space as desired features such as pedestrian plazas. 
Mixed use Street: Mixed use streets serve for industrial uses, as well as the growing number of residences, shops and services. Their use and character are in a state of constant change, and street must reflect this changing character and serve a variety of needs. Mixed use streets are often wide streets, with high volumes of fast-moving traffic. Streetscape treatment should include landscaping, pedestrian safety elements, public space uses, and other amenities to complement current and future land use.

\section{Case Studies}

\section{Chandigarh}

The city is designed by the French architect Le Corbusier. The primary module of a city's design is a sector. It is a self-sufficient unit having shops, school health centers and places of recreations and worship. The shopping street of the adjoining sectors, thus forming one long, continuous ribbon like shopping street.

The principle of planning was the automobile. The 7V's act in the town plan as the blood stream. These are an organized hierarchy of roads which can bring modern traffic circulation under control. The 7V's establishes a hierarchy of traffic circulation ranging from (7):

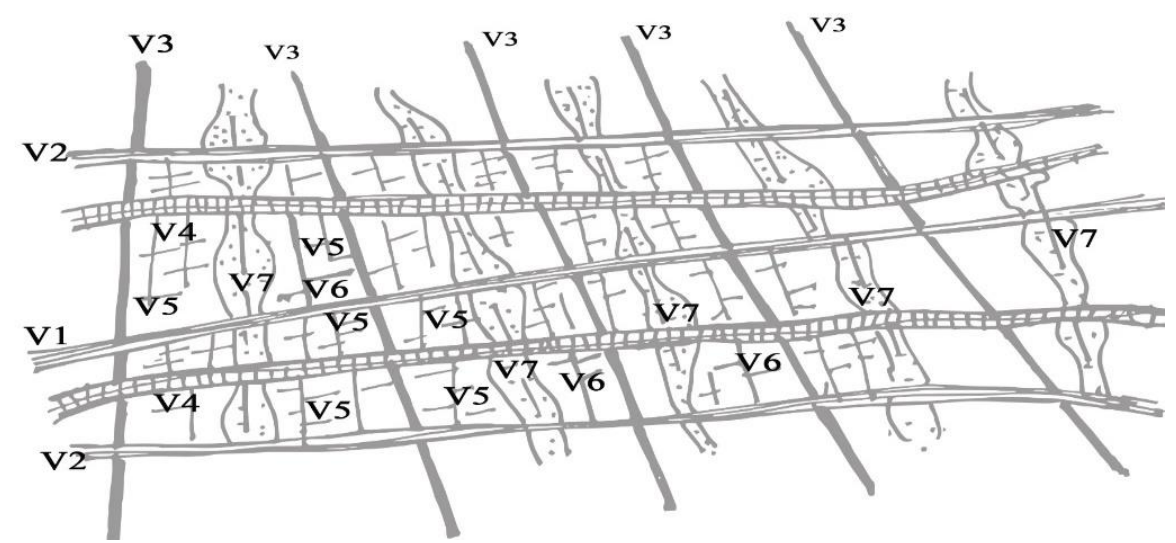

Figure 1: The division of 7 v's in Chandigarh planning, (hand sketched by the main author)

\begin{tabular}{|c|l|}
\hline TYPE & \multicolumn{1}{|c|}{ FUNCTION } \\
\hline V1 & Roads connecting Chandigarh with other cities in the region. \\
\hline V2 & $\begin{array}{l}\text { The major avenues of Chandigarh, with important institutional and commercial } \\
\text { buildings located on them. }\end{array}$ \\
\hline V3 & $\begin{array}{l}\text { Roads between sectors for fast moving vehicular traffic. Each sector is surrounded } \\
\text { either by V2 or V3 }\end{array}$ \\
\hline V4 & Shopping streets cutting through sectors with shops on their southern side \\
\hline V5 & Circulation roads within sectors \\
\hline V6 & Roads providing access to houses \\
\hline V7 & $\begin{array}{l}\text { Footpaths through green belts enabling pedestrians to cross sectors without having } \\
\text { to cross vehicular traffic and cycle tracks }\end{array}$ \\
\hline V8 & Cycle tracks through green spaces. \\
\hline
\end{tabular}

The case study emphasizes on the planning and the sections of different type of street according to its usage. 


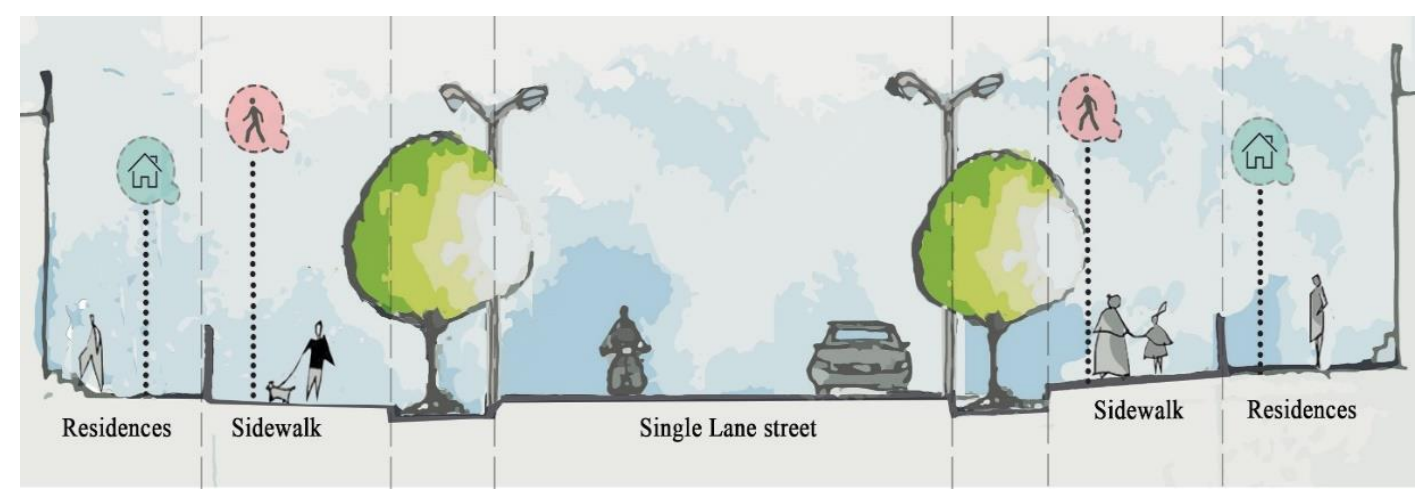

Figure 2: The section of V6 roads; (hand sketched by the main author)

This section is of V6 road that provide access to houses. These streets have proper visibility from the residences. The entrance of cars into the sectors, are exclusively reserved for family life so, no random people can come over these streets. Proper sidewalks are provided. The street is under the surveillance of the people residing there. The residences are low heighted and active frontages are provided in every residence. Low heighted boundary walls are provided to help visibility on streets. These types of streets are only restricted for residential units. Clear boundaries of the sectors are provided that encourage community 'ownership'. The street is well maintained as it belongs to the people living there. The streets have clear sightlines and good lightning. All these factors help in reducing the crime rate of these type of street and building a healthier environment to live. The people living here are very satisfied and happy with their living.

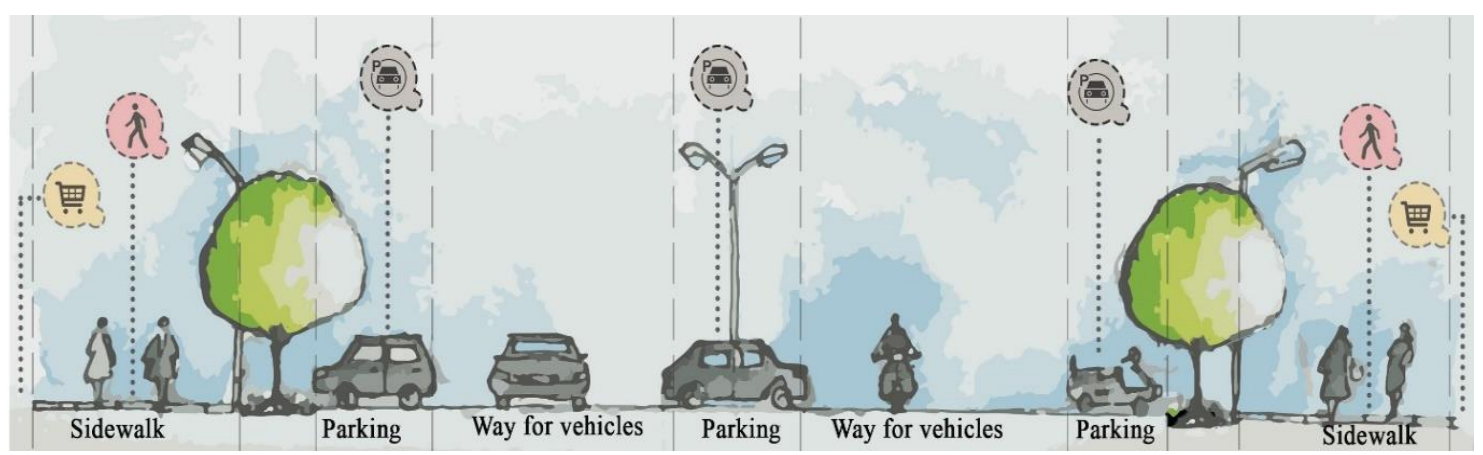

Figure 3: The section of V4 street (Sector 17 Marketplace); (hand sketched by the main author)

This section is of V4 streets. The section describes the marketplace of sector 17. The market is along the street. A well-designed parking space provided on both sides and on the center of the street for two wheelers and four - wheelers. Green Lanes are also provided on both side of the street for shrubs and trees. A wide sidewalk is also provided on both side of the street to serve marketplace. The sidewalk has the space for vendors and various temporary activities. In spite of, the street serves different kind of people and different activities, the street is safe to some extent because a proper zone is provided for each activity. According to the analysis, people like to hangout on that street as it has many activities and proper segregation of areas. Hence, the street is helping in reducing the urban stress level. 


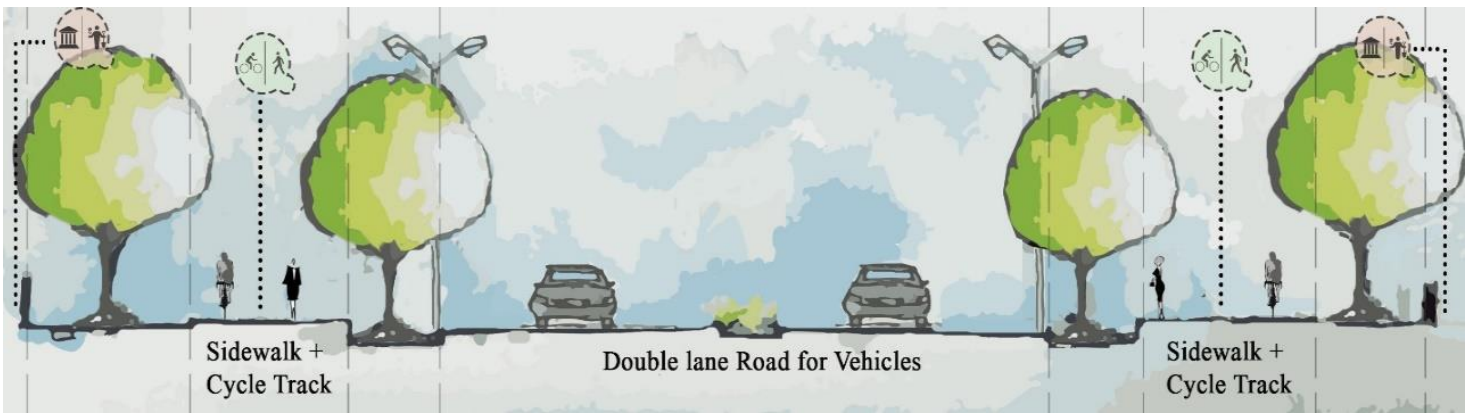

Figure 4: The section of V2 and V3 streets; (hand sketched by the main author)

This section is of fast-moving vehicular traffic street i.e. V2 and V3. These types of street surrounding comprises of public buildings, educational institutions, commercial buildings, gardens and the leisure valley. The street is double lane for vehicles, it also has two more lanes for cycle track and sidewalk on both the sides. According to the analysis, the street has proper light to serve the vehicle lane but not for the cycle track and pedestrian lane. The lane for pedestrian and cycle track are properly used in the day hours but not in the night hours. In the night hours these tracks become the space for unwanted activities. Because the main crowd is of the moving one and the spaces that surround the street are used in day hours, hence making the street dull at night. Due to this the street is not safe for the pedestrian during night hours.

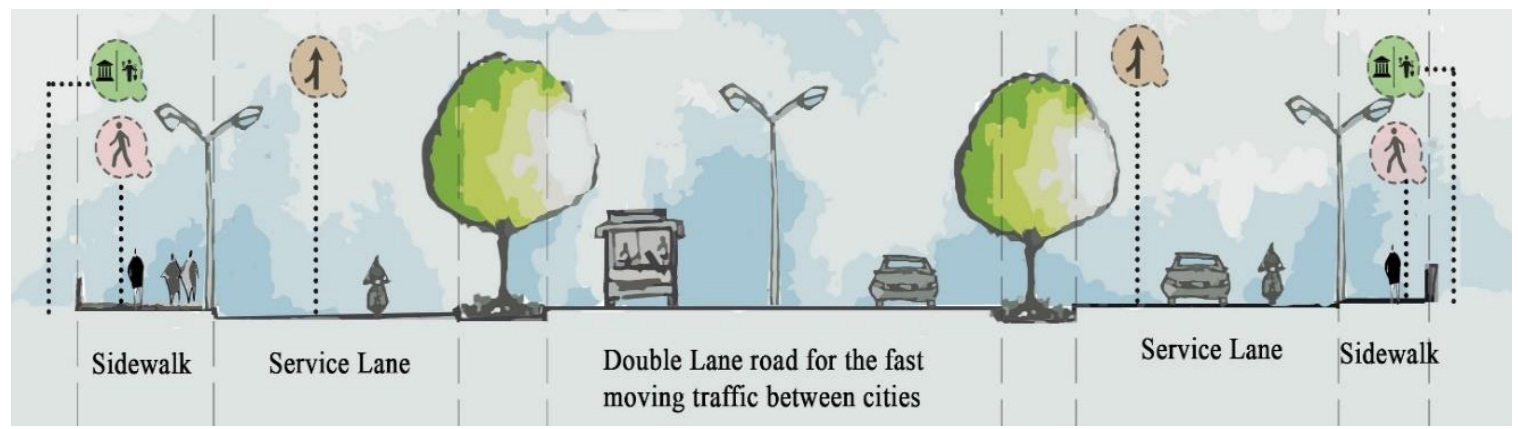

Figure 5: The section of V1 street; (hand sketched by the main author)

This section is of V1 Street that connects to the other towns. The city has the major crowd of fastmoving vehicles that move from one town to other. It also has the service lane with a sidewalk to serve the surrounding like kala gram and railway station. The street is all time busy as it connects the various high ways. But the service lane and sidewalks are dull, as it connects to the less activity areas and it is not safe during night hours.

\section{JM Road, Pune}

Jangli maharaj road is located in Pune. The surrounding of this road comprises of shops, restaurants and various food zones. It is a busy $1.5 \mathrm{~km}$ long one-way street. A 300-meter stretch of this street has a well-designed sidewalk. (8) 

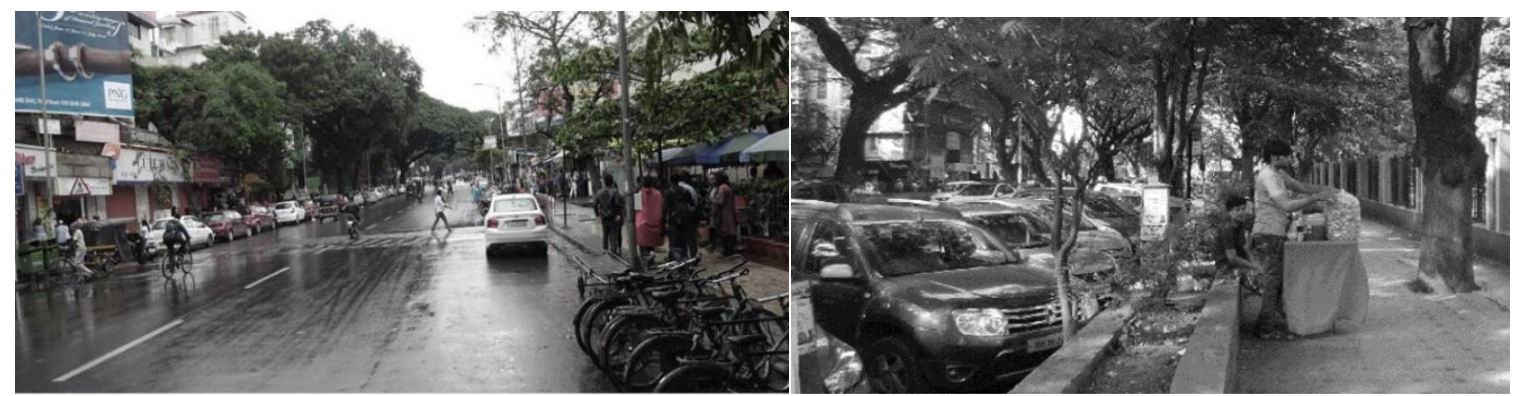

Figure 6: Old photographs of Jangli Maharaj Road., Source: http://oasisdesigns.org/pune.asp

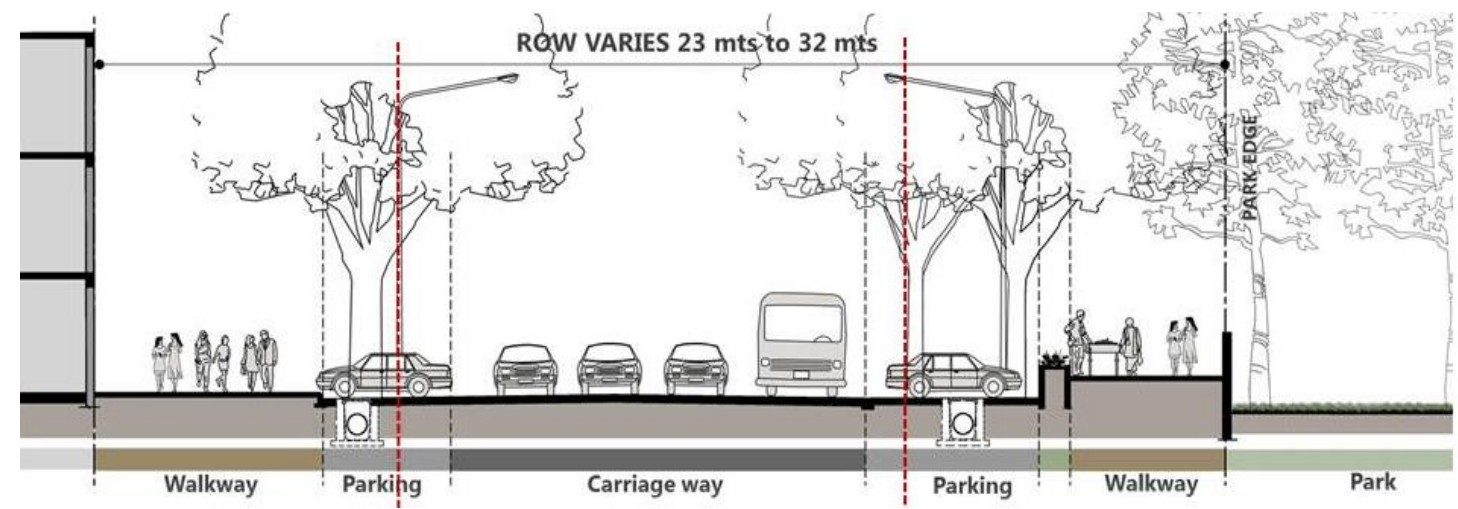

Figure 7: Old section of Jangli Maharaj Road.,

Source: http://oasisdesigns.org/pune.asp

Before the redesigning of the street side walk, the street faced many problems. Due to no parking space, the vehicles were parked along the street making no access to the sidewalks. There was no place for the vendors and pedestrian. As the street serve the shops and various eating zones it has the main crowd of pedestrian which was not properly served. The street also serves a park on a side. The park is not used during night hours so it became the zone for unwanted activities as the sidewalk which serve the park was dull. The sidewalks were not safe which lead to various thug and mugger cases. (9)

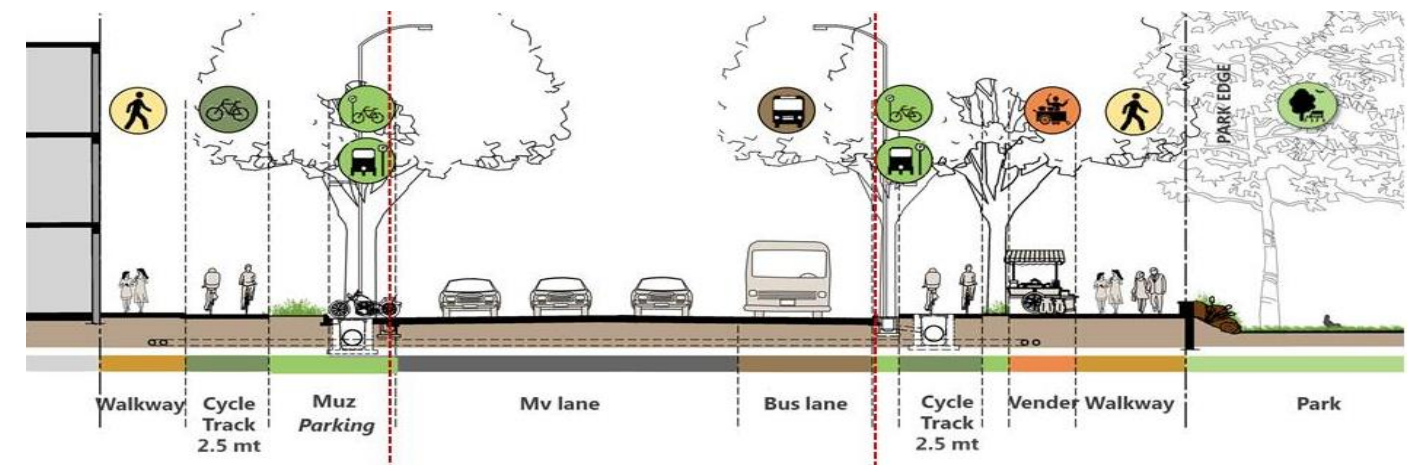

Figure 8: New section of Jangli Maharaj Road.,

Source: http://oasisdesigns.org/pune.asp

After the redevelopment of the street. The street now sports a cycle track and a much wider footpath, made by merging the frontage of the shops that line the stretch with the sidewalk and by streamlining the old haphazard parking. Green spaces serve as buffers to segregate the two modes 
of walking and cycling. "The design now celebrates the newly created public realm, giving people clear and buffered walking and cycling, and also incorporates outdoor seating areas for people to have a quick lunch, play areas for kids, and many seats for people to sit and enjoy the urban life of Pune," Better signage and street lighting are other features that collectively make JM Road a stellar example of street design in the country. The pedestrian policy adopted in this street, which now guides the development of high-quality pedestrian infrastructure, envisions Pune as a haven for those on foot. (9)

According to the analysis, the people enjoy to walk on this street as it serves various age groups and has well defined space for various activities. A large number of people come to enjoy the street during evening hours. This street became the safe and happy street of Pune as it helps in reducing the urban stress level of the city.
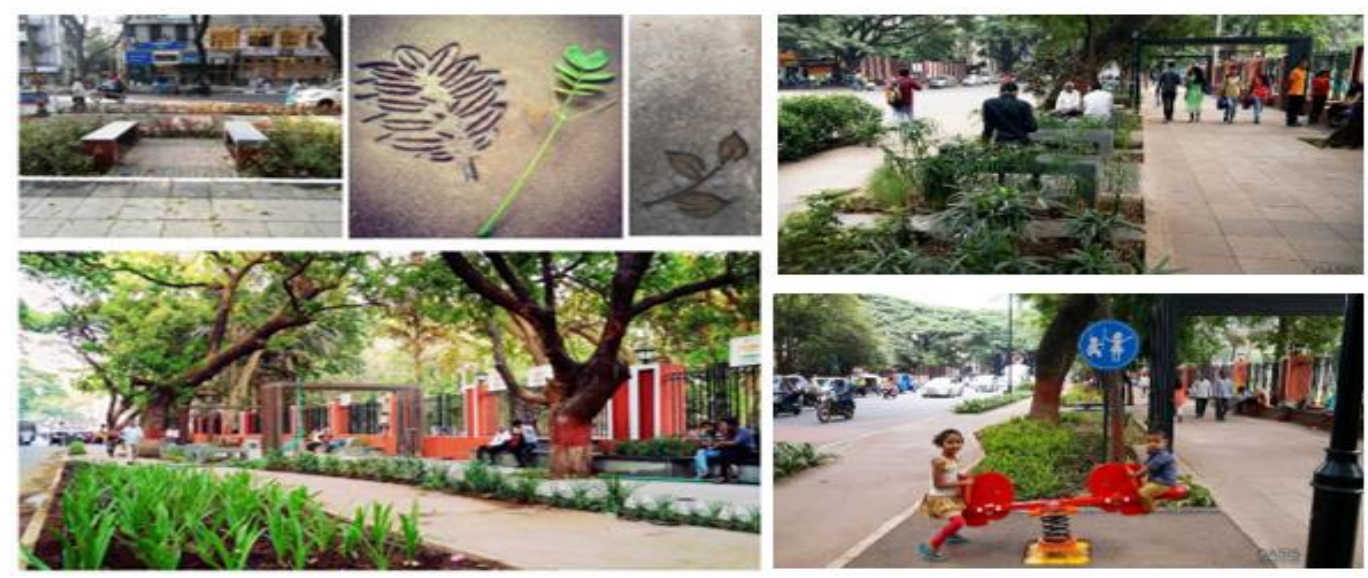

Figure 9: Present photographs of Jangli Maharaj Road

Source: http://oasisdesigns.org/pune.asp

\section{Survey Analysis}

According to the survey conducted by researcher, various questions were asked to the public of various cities of India.

The streets of India majorly have street lights, sidewalks, pedestrian movement are given very less importance in the street. According to this the streets which have more elements are safer than the other.

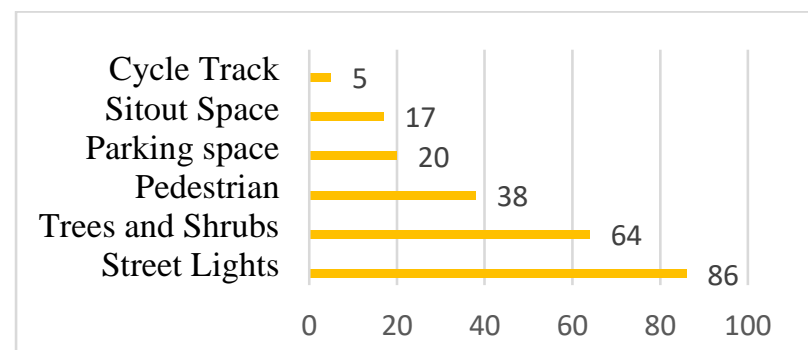

Figure 10: The percentage of street scape elements in Indian streets, (Analysis on the basis of the survey conducted by the researcher) 


\section{Analysis of Safety on Street According to Surrounding}

\section{Residential Street}

$\underline{\text { Low heighted residences }}$

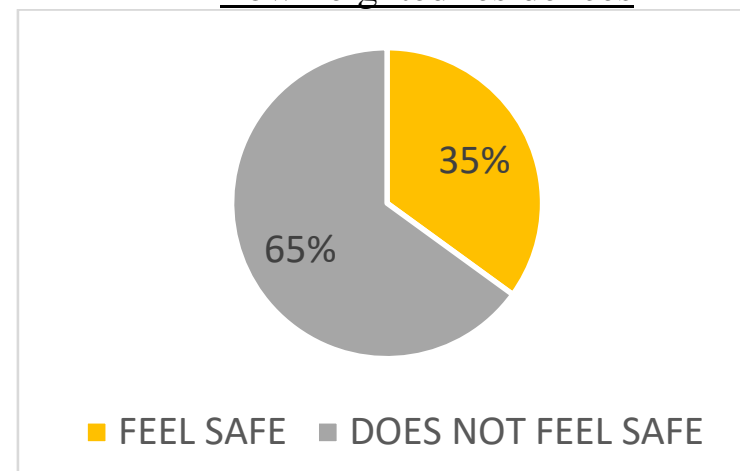

$\underline{\text { High rise Apartments }}$

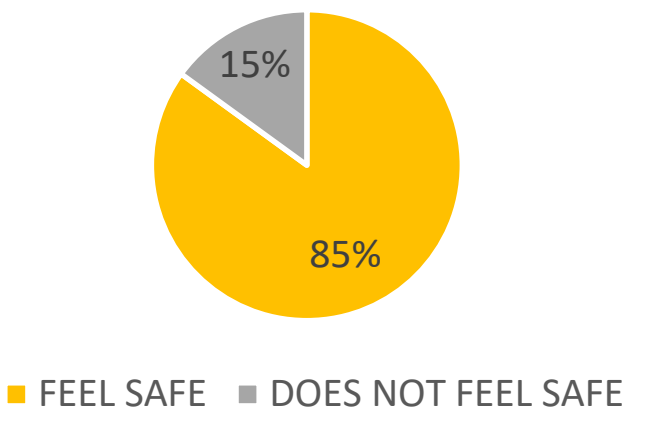

Figure 11: The percentage of safety on the street which have low heighted residences and highrise apartments, (Analysis on the basis of the survey conducted by the researcher)

According to this, the street which have low heighted residences are safer than the street which have high rise apartments. Because in the low heighted residences clear sightlines and maximum visibility is provided towards the street weather in the high rise the clear visibility of street is not possible.

\section{Mixed Use Street}

Major: Residences

Minor: Commercial/Educational/

Public buildings

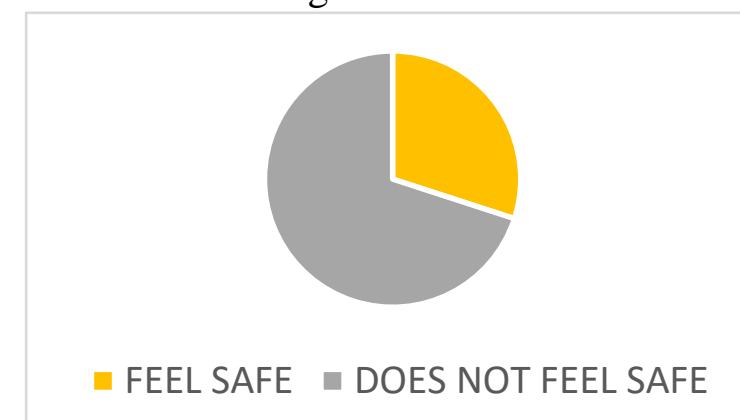

Major: Commercial /Educational / Public buildings Minor: Residences

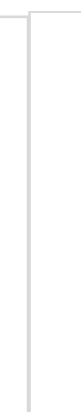

Figure 12: The percentage of safety on the mixed used street, (Analysis on the basis of the survey conducted by the researcher)

According to this graph, the street which have mixed use are safe. The street which have residences in the major and commercial and other activities are in minor are safer. Because the street is under the surveillance of the people residing there so no unwanted activity can take place. Whereas the street which have commercial and other activities are in major and residences are in minor is not safe, as these streets are majorly used in the day time and became dead at night hours. 


\section{Analysis of Safety on Street According to Vehicular and Non-Vehicular Zone}

According to this graph the street which is majorly used by pedestrian are safer because to keep an eye on the activities going on street is easy.

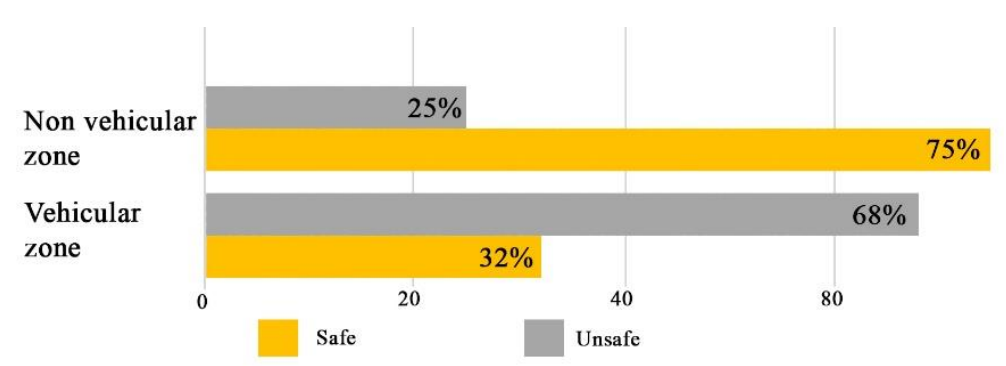

Figure 13: The percentage of safety according to vehicular and non-vehicular zone, (Analysis on the basis of the survey conducted by the researcher)

\section{Conclusion}

This research leads to a conclusion that sidewalks plays an important role in maintaining the function of a street. The sidewalks are not only the solution of creating good environment on the street but sidewalks should also be designed with various elements so that it can engage people and provide better and safe space of walking. Streets also play a major role in reducing the urban stress of a city as the place where you spend time has an impact on your mind. Rather than providing large parks which remain secluded most of the time, more attention needs to be paid on side walks and street scaping. Hence it must be taken as a final call to Urban Designers and Urban Planners for making our society safe and comfortable.

\section{Acknowledgements}

This research paper is a contribution and thought of not only the author or co-author entitled to be the researcher of the research but of every individual who enlightened and kindled the approach of the dissertation research. Foremost I would like to express my sincere gratitude to my dissertation head Er. Utkarsh Jain, dissertation sub-head Ar. Khushboo Lahori, dissertation guide and principal Ar. Soma Anil Mishra, for their courteous and determined efforts. Their keen attentiveness and scrutiny encouraged and validated my thoughts towards the approach. I would also like to offer my sincere thanks to my colleagues, all faculty members of college of architecture for their assistance. Finally, I would like to express my gratitude to my family, for making me capable of doing whatever I am able to do.

\section{References}

[1] https://www.aia.org/articles/1616-environmental-psychology-building-with-feelin:31

[2] http://psychologyonthestreet.com/

[3] Jane Jacobs, (1961). The death and the life of great American cities. United states: Vintage Publications.

[4] Ted talk : https://youtu.be/DZPMkXTOz8Q

[5] Cliff Moughtin, Urban Design: Street and Square

[6] https://issuu.com/cdaadmin/docs/bsp_book-small 
[7] http://chandigarhtourism.gov.in/

[8] http://oasisdesigns.org/pune.asp

[9] https://3gozaa3xxbpb499ejp301xc8-wpengine.netdna-ssl.com/wp-content/uploads/2018/02/InIndia-the-City-of-Pune-Takes-the-Lead-in-Making-Space-for-Transit-and-People.pdf

*Corresponding author.

E-mail address: kavya_trivedi@ outlook.com 